\title{
New Mexico Tech \\ Landmine, UXO, IED Detection Sensor Test Facility: Measurements in Real Field Soils
}

\author{
Jan M.H. Hendrickx ${ }^{* a}$, Nicole Alkov ${ }^{\mathrm{a}}$, Sung-ho Hong ${ }^{\mathrm{a}}$, Remke L. Van Dam ${ }^{\mathrm{b}}$, Jan Kleissl ${ }^{\mathrm{a}}$, Heather \\ Shannon $^{\mathrm{a}}$, John Meason ${ }^{\mathrm{a}}$, Brian Borchers ${ }^{\mathrm{a}}$, and Russell S. Harmon ${ }^{\mathrm{c}}$ \\ ${ }^{a}$ New Mexico Tech, 801 Leroy Place, Socorro, NM 87801, USA \\ ${ }^{\mathrm{b}}$ Michigan State University, East Lansing MI 48824 \\ ${ }^{\mathrm{c}}$ Army Research Office, Durham, NC, USA
}

\begin{abstract}
Modeling studies and experimental work have demonstrated that soil physical properties have a significant effect on most sensors for the detection of buried land mines. Where a modeling approach allows for testing the effects of a wide range of soil variables, most experimental work is limited to either field soils with poorly known properties or oversimplified conditions. With this in mind, we have constructed an outdoor test site with full control of soil water content and continuous monitoring of important soil properties and environmental conditions. In three wooden frames of $2 \times 2 \times 1$ meter, filled with different soil types (sand, loam, and clay), we buried low-metal anti-tank and antipersonnel land mine simulants. Time domain reflectometry sensors and thermistors measure soil water content and temperature, respectively, at different depths above and below the land mines as well as in homogeneous soil away from the land mines. The test site has been in operation for two years, during which time the soils have evolved to reflect real field soil conditions. In this contribution we compare visual observations as well as ground-penetrating radar and thermal infrared measurements at this site taken immediately after construction in early 2004 with measurements taken in early 2006. ADD CONCLUSIONS
\end{abstract}

Keywords: land mine test lane, detection, spatial variability, temporal variability, climatic conditions, thermal infrared, ground penetrating radar

\section{INTRODUCTION}

Many programs are ongoing to develop new methodologies for efficient detection of buried land mines. These methodologies can be grouped in three main categories:

(1) Sensors that detect anomalies in the subsurface through scattering or transformation of transmitted energy. Sensors in this category include metal detectors and active microwave techniques, such as ground penetrating radar (GPR).

(2) Sensors that detect surface anomalies, caused by buried objects. Passive thermal infrared is the primary technique in this group.

(3) Sensors that detect the land mine explosives or chemicals that are associated with the explosives. In this group fall chemical sniffers (artificial dogs), biological detectors (animals and genetically altered plants), molecular radio frequency resonance absorption spectroscopy, and nuclear radiation methods.

Most of these technologies, apart from the metal detector, are not in widespread use. Even though GPR seems to be making a careful entrance in the humanitarian demining user community[1], all sensors (including GPR and metal detectors) experience difficulties reducing their false alarm rates while maintaining a large probability of detection under all conditions. Spatial and temporal variability in soil conditions are among the primary causes for non-optimal performance of sensors, discrimination algorithms, and sensor fusion algorithms. 
Soil moisture content is one of the most important soil parameters to consider because it controls or influences many other soil properties such as the dielectric constant, electrical conductivity, thermal conductivity, heat capacity, and vapor diffusion rates. The natural variability in water content around land mines can be extreme [2, 3]. As a result, many sensors from GPR [4], to infrared [5], and chemical sniffers [6, 7] are affected by changes in water content. Recent modeling studies and field experiments at New Mexico Tech have predicted and shown these effects for ground penetrating radar and thermal infrared [8-12]. The soil texture and environmental conditions (precipitation, evapotranspiration, wind velocity, radiation, and temperature) are other important factors in explaining the variability in soil conditions. To get a better understanding of these effects on land mine detections sensors it is necessary to be able to accurately monitor, or in some cases control, these conditions. For this reason we decided in 2003 to build an outdoor test site focusing on monitoring the soil and environmental variability. Immediately after construction of the facility the soils were disturbed and more similar to laboratory soils than real field soils; now more than two years later the soils have been exposed to the elements and have become similar to real field conditions such as encountered in many abandoned mine fields worldwide. The main objectives of this study are (i) to describe soil changes that we have observed and (ii) to compare thermal images and ground penetrating radar measurements taken in early 2004 with those taken in early 2006.

\section{RATIONALE}

The land mine detection community already has a large number of and variety in available test facilities. For example the U.S. Army Night Vision and Electronic Sensors Directorate (NVESD) at Fort Belvoir, VA, have a facility equipped with lanes of different soil types [13]. Many army bases in the United States, including Jefferson Proving Grounds, Aberdeen Proving Grounds, Yuma Proving Grounds, and Shofield Barracks have extensive testing lanes. At New Mexico Tech we have the Energetic Materials Research and Testing Center (EMRTC) that focuses on fundamental and applied research of energetic materials. EMRTC operates a 40 square mile field laboratory that contains over 30 test sites, gun ranges, storage sites, and other research facilities, allowing for a complete spectrum of research and testing activities. Its Countermine Test Site (Fig. 1) was developed to test and evaluate technologies for the detection and destruction of anti-tank and anti-personnel mines. The site consists of support facilities and 100-and 200-meter oval flat tracks. Inert or live mines can be located on the tracks. Remote-operated robotic detection/destruction devices can be used for operations involving live mines. JOHN MEASON ADD LIST OF PAPERS AND/OR SENSOR DEVELOPMENT PROJECTS IN WHICH CTS HAS BEEN USED.
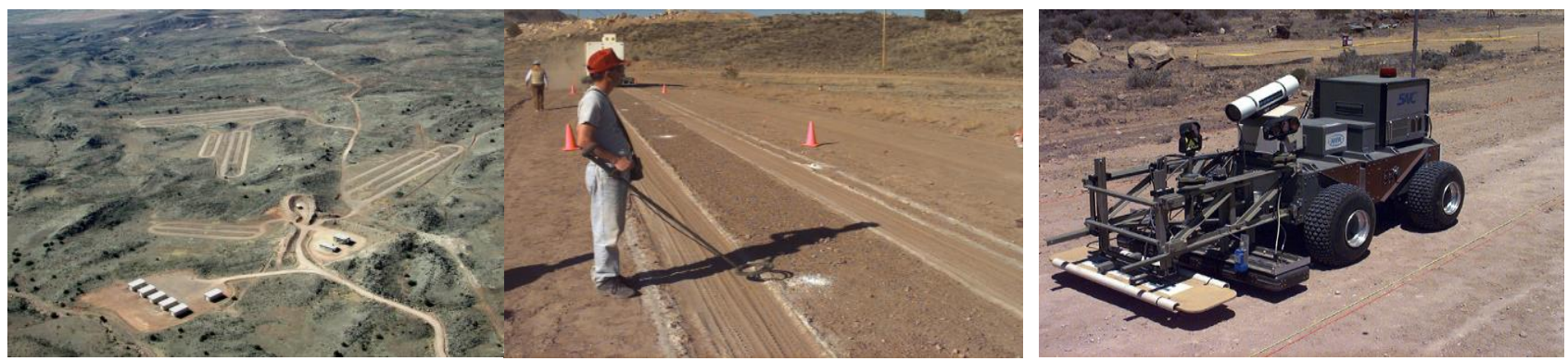

Figure 1. Countermine Test Site of the Energetic Materials Research and Testing Center of New Mexico Tech.

While the testing lanes described above are providing realistic -albeit limited- test conditions to evaluate and further develop different land mine detectors, several universities and national laboratories have active programs directed to the development and improvement of existing and novel land mine detectors. Most of these research teams focus on their specific detector and conduct only limited tests in soils without extensive monitoring of soil and environmental conditions. A typical research group is the one headed by Hendrickx and Borchers who have more than seven years experience with the investigation of land mine detection phenomenology. They have used and further developed simple analytical equations and numerical models describing the physics of landmine-soil-sensor systems for the prediction of land mine detector responses in field soils worldwide. For the evaluation and improvement of these models an outdoor Landmine Detection Sensor Test Facility was started in 2003 with support of the Army Research Office and a grant 
from the Defense University Research Instrumentation Program (DURIP). Co-author Van Dam directed the implementation of the first three soil boxes; different soils will be added in the future (Fig. 2). The first three soil boxes are the subject of this study; they have given us a wealth of experience on how to monitor soil and environmental variables around landmines, UXOs, and IEDs in spatially and temporally variable field soils.

Most academic research groups rarely have the opportunity to work with live explosives for lack of skilled personnel and safety measures. Yet, the recent work on land mine detection phenomenology has clearly shown the need for detailed monitoring studies in real field soils with real explosives under a wide range of environmental conditions. Therefore, co-authors Meason, director of EMRTC, and Hendrickx have joined forces and are merging over fifty years of expertise in explosives research and testing at EMRTC with the capabilities of Hendrickx's research group in monitoring soil and environmental conditions around landmines. They now offer New Mexico Tech's Outdoor Test Facilities to public and private entities for testing landmine, UXO, and IED detection sensors using either live explosives or simulants. Soil conditions are available from clay to sand texture, dry to wet, saline to non-saline, magnetic to non-magnetic, vegetated to bare soil. We also have the opportunity to establish test sites in areas with shallow water tables or in semi-urban environments. Environmental variables that are measured include: net radiation, sensible and latent heat fluxes, soil heat flux, air humidity, wind speed, air temperature, vapor pressure deficit, soil temperature, soil water content, soil salinity. Other variables can be added where needed such as $\mathrm{CO}_{2}$ or TNT concentrations. We not only have capabilities to measure the components of the energy balance on the ground but our research group also uses using satellite images covering large areas[14-18]. The results of this study again underline the big need for an integral test site for the investigation of the complex relations between detection sensors and landmine, UXO, and IED phenomenology.

a)

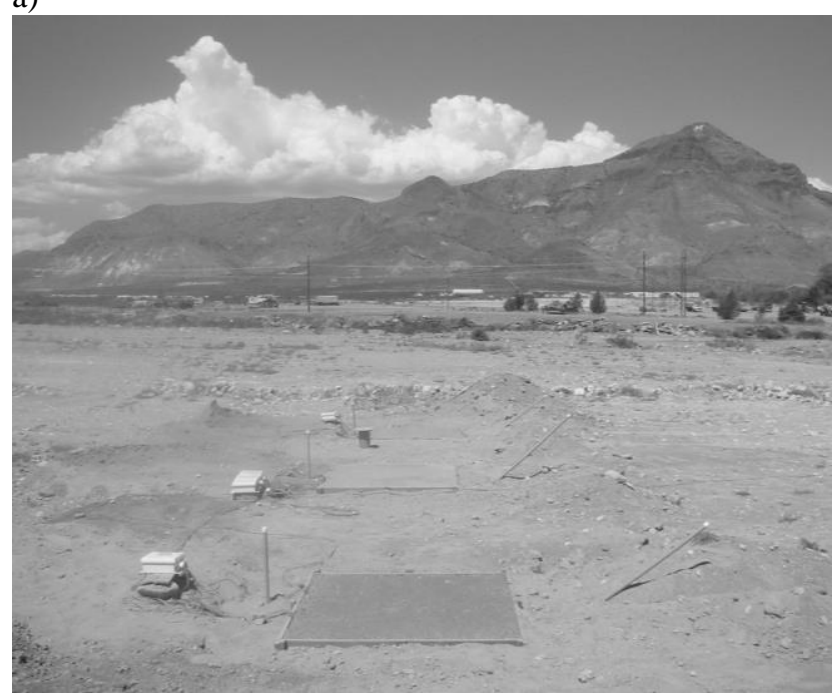

b)

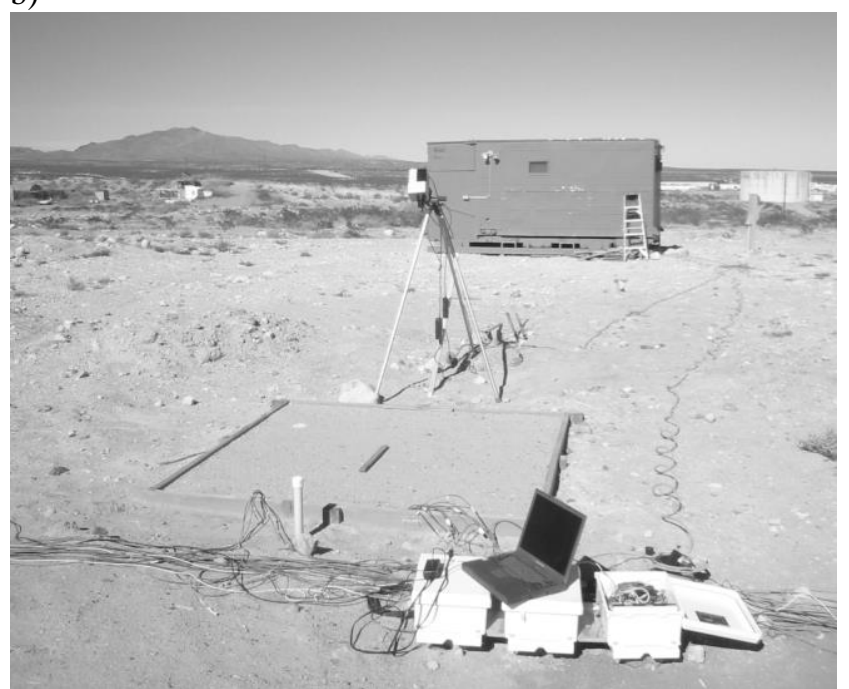

Fig. 2. a) The outdoor Landmine Detection Sensor Test Facility at New Mexico Tech at the foot of "M-mountain". b) The setup in detail with datalogger and sensor control in the white boxes in the foreground and the field office in the background. Pictures by R.L. van Dam, early 2004.

\section{DESIGN AND FACILITIES}

\subsection{The general setup and material}

We have set up three test boxes of $2 \times 2 \times 1$ meter dimensions (Fig. 2). The boxes have been filled with well-sorted sand, a typical loam soil with some $(<5 \%)$ larger gravel, and a clay soil ( $70 \%$ clay-size fraction). In each of the three wooden boxes 2 anti-tank (AT) mine simulants and 4 plastic anti-personnel (AP) mine simulants have been buried. The AT mine simulants were buried with their tops at 0.05 meters depth in the north-east and south-east quadrants of the 
boxes. The AP mine simulants were buried in the north-west quadrants of the boxes, at the surface, and at $0.02,0.04$, and 0.06 meters depth (Fig. 3). Each box is equipped with 8 sensors for soil moisture content and 8 soil temperature sensors, and were all placed in the southern half of the boxes (Fig. 3). Five sensors of each are placed above and below the buried AT mine simulant; at 0.02, 0.2, 0.3, 0.4, and 0.5 meters depth. In the undisturbed soil in the south-western quadrant 3 probes of each were installed at $0.02,0.2$, and 0.5 meters depth. The boxes are equipped with a PVC tube in which a metal rod can be placed (for GPR time-depth conversion). The tubes run north-south at 0.5 meter depth (Fig. 3).

Sprinkler system - In order to control the soil moisture content we use a $3 \times 3 \times 1$ meter sprinkler system, constructed using PVC plastic tubing. The steel center pipe has Rain Bird XS-360TS-1032 sprinkler nozzles attached to it. The system has been tested successfully to distribute moisture homogeneously over a $2 \times 2$ meter area [19].

Land mines - The AT land mine simulants used are completely inert and composed of Dow Corning 3110 RTV silicon rubber. They have been designed to simulate a Netherlands land mine of type NR26, which is a nonmetallic land mine and measures 0.3 meter in diameter and 0.12 meter in height. The TNO Physics and Electronics Laboratory in the Netherlands manufactured these land mines. The anti-personnel land mine simulants have been manufactured by New Mexico Tech using silicon rubber and a plastic casing. The mines have an air gap on top of the rubber. Schematic diagrams with dimensions of the land mine simulants have been published before ????

\section{Top view:}

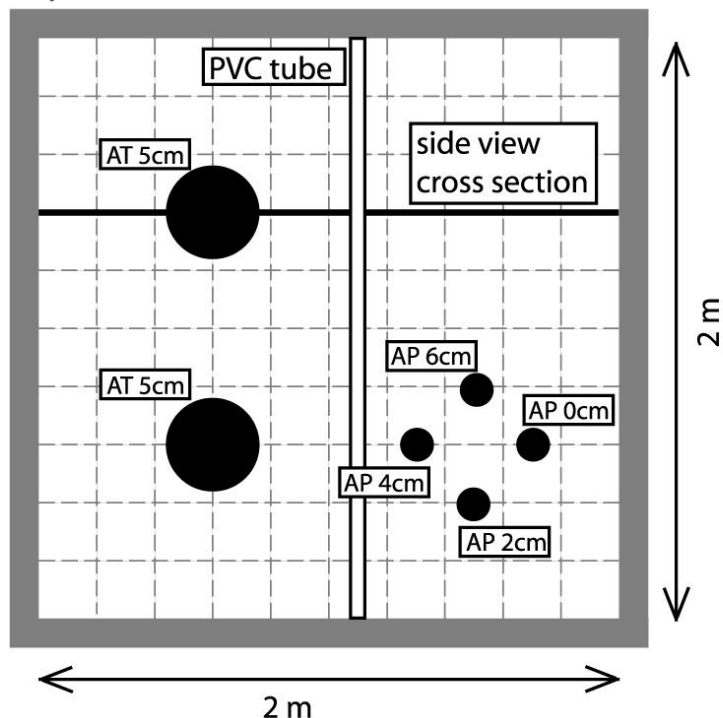

Side view:
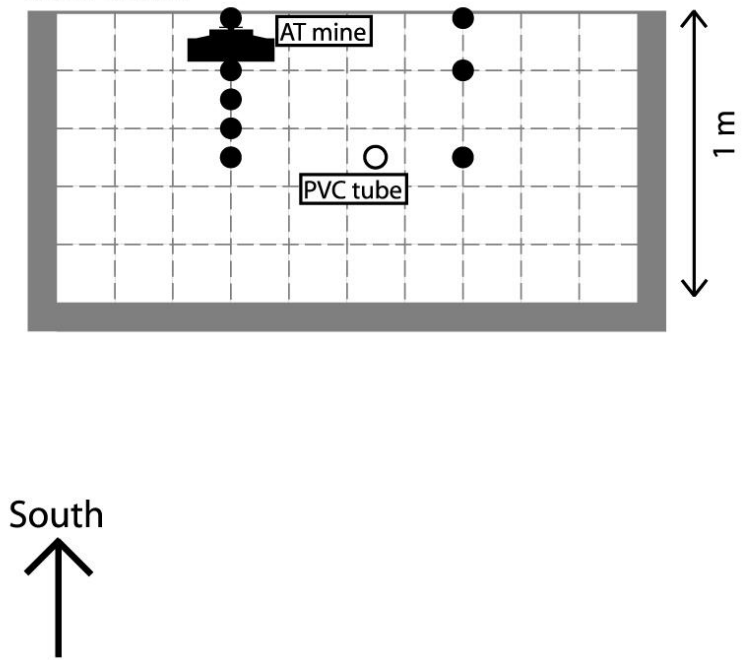

Fig. 3. Layout of the test plots at the NMT land mine detection test facility. In the side view, the open circle marks the location of the PVC tube. The black circles mark the locations of the temperature and soil moisture sensors.

\subsection{Sensors}

\subsubsection{Weather station}

The site has a fully equipped weather station for continuous monitoring of all relevant atmospheric conditions. The weather station is equipped with a net radiometer, a sonic anemometer, a rain gauge, a thermocouple, and an hygrometer. The net radiometer measures the difference between incoming and outgoing short-wave and long-wave radiation. The incoming radiation consists of direct and diffuse solar radiation plus long-wave irradiance from the sky. The outgoing radiation consists of reflected solar radiation plus the long-wave radiance from the soil. The anemometer measures turbulent fluctuations of wind speed and speed of sound on three nonorthogonal axes. The wind speeds are transformed into the orthogonal wind components (i.e., horizontal wind speed and direction) while the speed of sound is used to determine the ambient air temperature. The thermocouple measures air temperature at a height of two meters 
above the ground. The sensitive hygrometer measures rapid fluctuations in atmospheric water vapor. The combination of data from the sonic anemometer, the hygrometer, the thermocouple, and the net radiation, plus an estimate of the soil heat flux is used to calculate the evapotranspiration (ET). The tipping bucket rain gauge measures precipitation at 0.01 inch increments.

\subsubsection{Soil sensors}

It is essential to be able to continuously measure soil moisture conditions and soil temperatures above and below the land mines and away from them in homogeneous soil. For this we installed time domain reflectometry (TDR) probes and temperature sensors at different depths and locations in the test boxes (Fig. 3), and connected them to a datalogger for continuous monitoring.

\subsubsection{Geophysical sensors}

Infrared camera - We use a ThermaCAM SC3000 infrared (IR) camera manufactured by FLIR Systems Inc., Sweden, for measurement of the apparent temperature of the soil surface above and away from the buried land mines. This IR camera has a spectral range from 8 to $9 \mu \mathrm{m}$ with thermal sensitivity of $0.03{ }^{\circ} \mathrm{C}$ at $+30{ }^{\circ} \mathrm{C}$. It uses a quantum well infrared photon detector. The raw thermal IR images are analyzed using the software provided by FLIR, and using standard spreadsheet programs. In 2006, thermal camera images were taken before and after removal of the dry vegetation covering the plots. Use of thermal cameras before vegetation removal is typical for mine clearance operations.

Ground penetrating radar - For ground penetrating radar (GPR) measurements we use a pulseEKKO1000 system manufactured by Sensors\&Software, Canada. The system is equipped with 450, 900 and $1200 \mathrm{MHz}$ antennae. To accurately guide the GPR system over the land mine plots, we use a wooden positioning frame. Mounted in this frame, the transmitting and receiving antennae are elevated about $4 \mathrm{~cm}$ above the surface. Since the radar needs to be as close to the soil surface as possible, typically vegetation is removed before using GPR sensors. We have followed this procedure in this study.

Bartington Magnetic Susceptibility - Magnetic susceptibility is an important soil characteristic for metal detectors. We have made considerable progress with the development of a conceptual model for the prediction of magnetic susceptibility worldwide. Therefore, we have measured the magnetic susceptibility of our three test boxes in order to compare them with the magnetic susceptibility of soils worldwide. Magnetic susceptibility measurements need to be taken close to the soil surface in order to prevent the influence of distance above soil surface on measurements. In this study nine measurements were taken on each soil before vegetation was removed. The measurements were taken at equal distances over the soil surface, moving the sensor when vegetation was interfering.

\section{COMPARISON OF SOIL-LANDMINE PHENOMENOLOGIES IN 2004 AND 2006}

\subsection{Visual Observations}

The soil surfaces in the three boxes changed considerably between 2004 and 2006 due to being exposed to the elements for two years. Immediately after installation the soil surfaces of the three boxes were flat and very homogeneous (Fig 4). After two years all three boxes exhibited a soil surface that was not homogeneous anymore. The sand and silt surfaces show a mini-relief but much less than the clay surface (Fig. 5); the clay surface showed deep cracks and a mini-relief with elevation differences of $10 \mathrm{~cm}$ or more (Fig. 6). The sand and silt surface have obtained a thin crusty surface, partly broken and partly covering the soil. Most likely this crust has been formed by input from fine dust; once the dust has been deposited it may disperse when precipitation is occurring forming the crust. The clay surface has a definitive mini-relief caused by the swelling and shrinking action of the clay soil during wetting and drying. Several of the AP mines were moved up and deposited on the soil surface. In addition, deep cracks have developed in the dry clay soil. Another change is the establishment of vegetation on the soils. The water retention capacities of the sand and silt soils are limited and not much vegetation did develop on these soils. However, the clay soil due its large water retention capacity allowed the development of relatively much vegetation (Fig. 6a). 


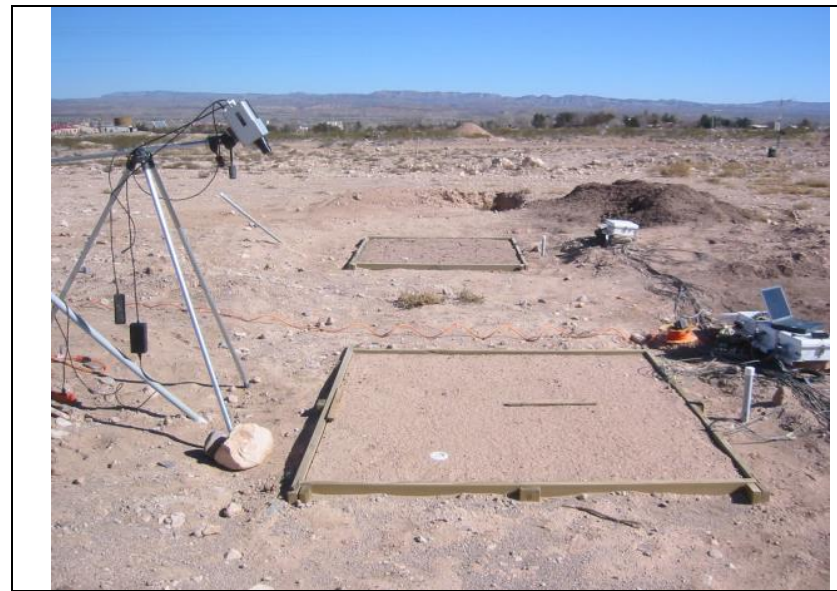

Figure 4a. The silt (front) and clay (back) box in early 2004 without any mini-relief and vegetation.

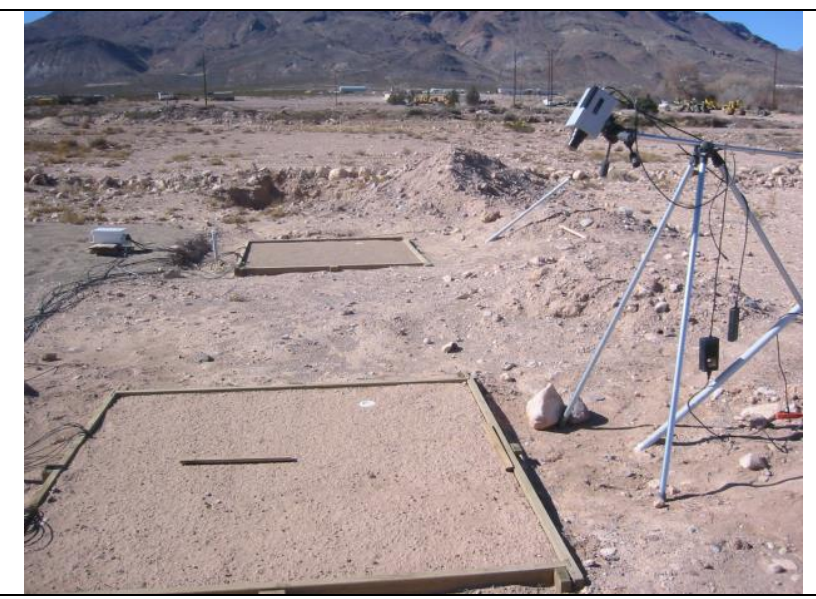

Figure 4b. The silt (front) and sand (back) box in early 2004 without any mini-relief and vegetation.

\subsection{Magnetic Susceptibility}

The magnetic susceptibility has been measured in 2006 when the Bartington Susceptibility Meter was available. However, studies reported in the literature indicate that few if any magnetic susceptibility changes are expected over a time period of two years. Table 2 presents the measurements. The magnetic susceptibility is not as low as found in some sedimentary leached materials (refer to Suriname and other places) due to the occurrence of volcanic rocks in New Mexico.

Table 2. Magnetic susceptibility in the three soils measured early 2006 using the Bartington Magnetic Susceptibility Meter.

\begin{tabular}{|c|c|c|c|}
\hline Location & Sand & Silt & Clay \\
\hline & Magnetic Susceptibility * 10?? & & \\
\hline 1 & & & \\
\hline 2 & & & \\
\hline 3 & & & \\
\hline 4 & & & \\
\hline 5 & & & \\
\hline 6 & & & \\
\hline 7 & & & \\
\hline 8 & & & \\
\hline 9 & & & \\
\hline Mean & & & \\
\hline Standard Deviation & & & \\
\hline Coefficient of Variation & & & \\
\hline
\end{tabular}

\subsection{Thermal Images}

Figure 7 presents the air temperature and wind speed during the measurements with the thermal camera. During March 10-12 the maximum and minimum air temperatures do not differ much due to cloudiness; the other days March 13-19 show a nice range of air temperatures indicating relatively good conditions for thermal imaging of landmines. Wind speeds during the day were exceeding $4 \mathrm{~m} / \mathrm{s}$ and sometimes reached $12 \mathrm{~m} / \mathrm{s}$ which is typical in New Mexico during March.

Figure 8 shows a typical thermal image reflecting 2006 soil conditions. Compared to the thermal images that we measured in 2002 and 2004 over smoothed homogeneous soil surfaces, this thermal image of the silt box shows a large spatial variability of soil surface temperatures. The increased spatial variability of soil surface temperatures is caused by the uneven soil surface and the crust formation. The uneven soil surfaces will lead to different soil moisture contents due to differences in infiltration. Different soil moisture conditions result in different thermal properties and, thus, different temperatures under otherwise identical environmental conditions. The uneven soil surface also results in different (mini) slopes and aspects and, therefore, different amounts of solar radiation received. For example, a north 
facing (mini) slope will receive less solar radiation and have a lower surface temperature than a south facing slope. Finally, the soil crust may also contribute to the temperature variability. Where the soil crust is connected tightly to the subsoil, surface temperatures will tend to be less extreme since the soil heat flux can penetrate deeper into the soil profile. However, where the crust has come loose from the subsoil an air gap exist that will prevent the heat flux to move deeper into the soil. As a consequence the surface temperature of the "loose" crust will be much higher than the temperature of a "connected" crust. During the night the effect will be reverse and the "loose" crust will have lower temperatures than a "connected" crust. Obviously, the higher spatial variability of soil surface temperatures will make it more difficult to detect thermal signatures of landmines, UXO's, and IED's.

Figure 9 shows the two thermal images in the clay box before and after removal of the vegetation. Again the microrelief, cracks, and soil crust are causing a large spatial variability of soil surface temperatures. Removal of the vegetation clearly reduces the spatial variability (compare Fig. 9a versus 9b) but has not enabled to detect the buried mines in this box. Only the two mines exposed at the soil surface could be clearly detected using the thermal camera.
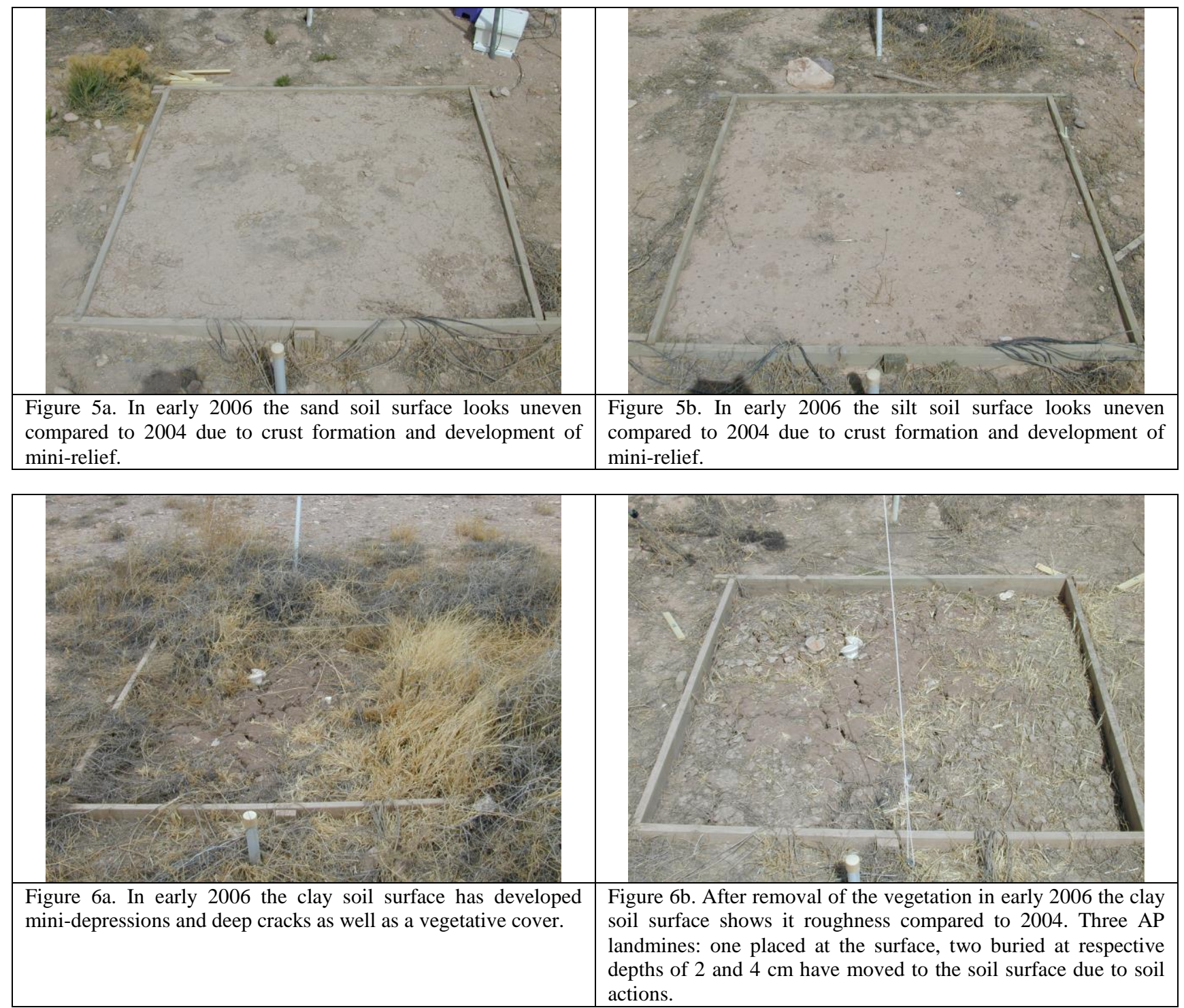

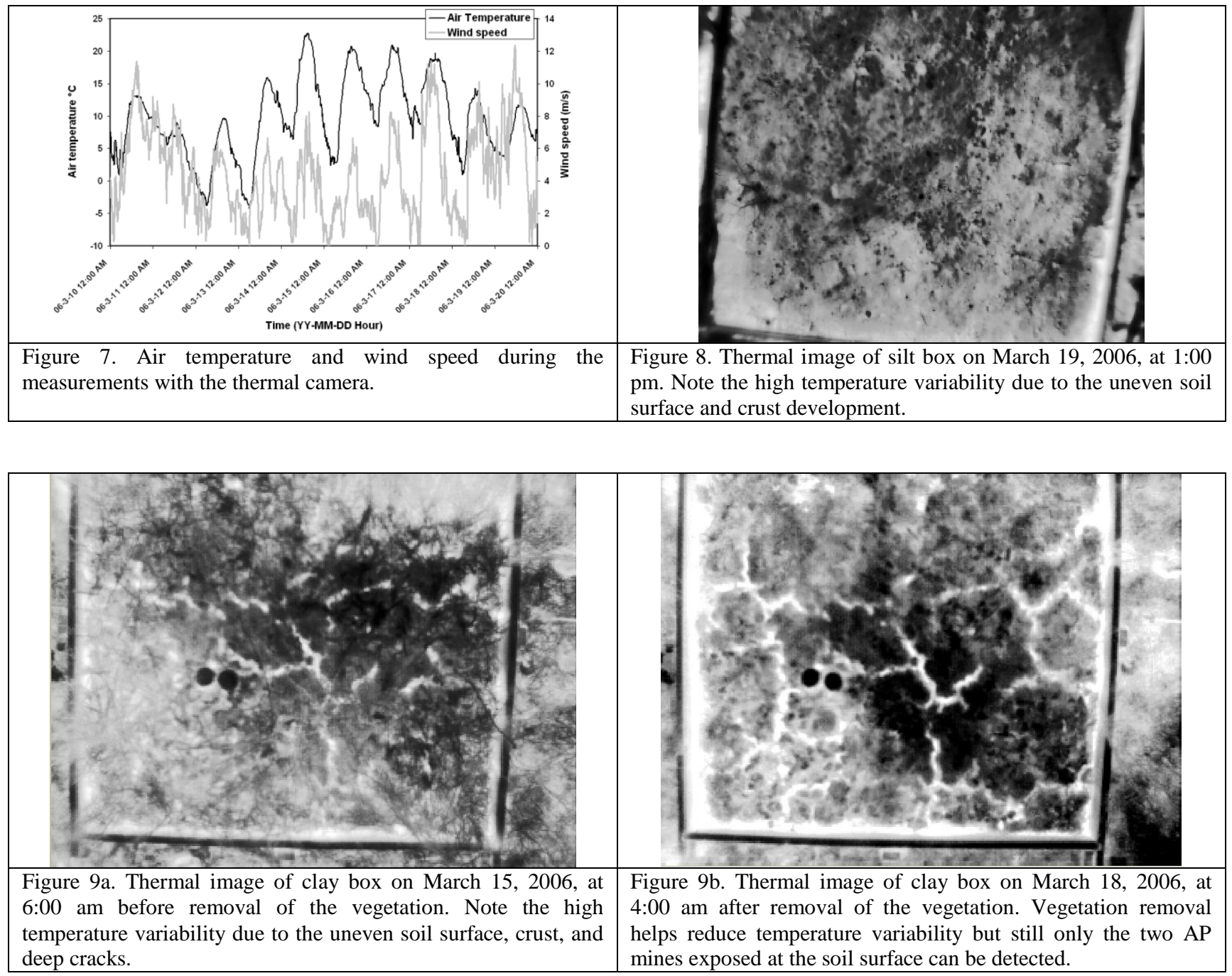

\subsection{GPR Measurements}

Figures 10 and 11 present the GPR images in 2004 and 2006 for, respectively, the sand and the clay box.

Remke I propose we focus our discussion here on the effects of the uneven clay soil surface. Sand seems to be ok, even with the more uneven and variable soil surface. What about the clay?

\section{CONCLUSIONS}

In this study we document changes in landmine phenomenology when soil surfaces change from artificial homogeneous conditions -typical for many tests of landmine detection sensors- to the much rougher conditions of real field soil surfaces. The latter are characterized by mini-reliefs, "loose" and "connected" soil crusts, cracks in clay soils, and vegetation. The spatial variability of soil surface characteristics of real field soils is much higher than the variability of artificial homogeneous soils. This increased variability leads to a much higher spatial variability of soil surface temperatures and a much lower probability to detect thermal landmine signatures. 
Discuss radar

We conclude that thermal imaging is very sensitive for the increased variability of real soil surfaces, GPR is less sensitive but may be affected also when the soil surface becomes quite uneven as is often the case in fine textured soils. No to very little effect is expected for sensors that are affected by magnetic soil susceptibility of soils.

In the clay soils the mines have moved to the soil surface; this may be some kind of an advantage since landmines close to the surface are easier to detect.

The New Mexico Tech land mine detection facility is especially designed to study the effects of spatial and temporal variability in environmental conditions and soil properties on land mine detection sensors. For this we have constructed an outdoor site at which land mine simulants have been buried in characteristic soil types: sand, loam, and clay. At the site climatic conditions are continuously monitored using a fully equipped weather station. Important soil properties such as moisture content and temperature are monitored using probes buried at different depths around and away from buried land mine simulants. The site is easily accessible and anyone interested is welcome to use it for testing their equipment.

\section{ACKNOWLEDGEMENTS}

The work at New Mexico Tech was funded by a grant from the Army Research Office (DAAD19-02-1-027) and partial support by the Energetic Materials Research and Testing Center of New Mexico Tech.

\section{REFERENCES}

1. $\quad$ McFee, J.E., Y. Das, and A.A. Faust. Defence $R \& D$ Canada research on nuclear methods of landmine detection. in Detection and Remediation Technologies for Mines and Minelike Targets VIII. 2003. Orlando: SPIE.

2. Hendrickx, J.M.H., B.S. Das, and B. Borchers. Modeling distributions of water and dielectric constants around landmines in homogeneous soils. in Detection and Remediation Technologies for Mines and Minelike Targets IV. 1999. Orlando: SPIE.

3. Das, B.S., B. Borchers, and J.M.H. Hendrickx, Modeling transient water distributions around landmines in bare soils. Soil Science, 2001. 166(3): p. 163-173.

4. $\quad$ Borchers, B., et al. Enhancing dielectric contrast between land mines and the soil environment by watering: modeling, design, and experimental results. in Detection and Remediation Technologies for Mines and Minelike Targets V. 2000. Orlando: SPIE.

5. Simunek, J., J.M.H. Hendrickx, and B. Borchers. Modeling transient temperature distributions around landmines in homogenous bare soils. in Detection and Remediation Technologies for Mines and Minelike Targets VI. 2001. Orlando: SPIE.

6. $\quad$ Phelan, J.M., et al. Laboratory data and model comparisons of the transport of chemical signatures from buried landmines/UXOs. in Detection and Remediation Technologies for Mines and Minelike Targets V. 2000. Orlando: SPIE.

7. Phelan, J.M., et al. Effect of soil wetting and drying on DNT vapor flux - laboratory data and T2TNT model comparisons. in Detection and Remediation Technologies for Mines and Minelike Targets VI. 2001. Orlando: SPIE.

8. Van Dam, R.L., et al. Soil effects on thermal signatures of buried nonmetallic landmines. in Detection and Remediation Technologies for Mines and Minelike Targets VIII. 2003. Orlando: SPIE.

9. Hendrickx, J.M.H., et al., Soil effects on ground penetrating radar detection of buried nonmetallic mines, in Ground Penetrating Radar in Sediments, C.S. Bristow and H.M. Jol, Editors. 2003: London.

10. Hong, S., et al. Land mine detection in bare soils using thermal infrared sensors. in Detection and Remediation Technologies for Mines and Minelike Targets VII. 2002. Orlando: SPIE. 
11. Miller, T.W., et al. Effect of soil moisture on landmine detection using ground penetrating radar. in Detection and Remediation Technologies for Mines and Minelike Targets VII. 2002. Orlando: SPIE.

12. Hong, S., et al. Impact of soil water content on landmine detection using radar and thermal infrared sensors. in Detection and Remediation Technologies for Mines and Minelike Targets VI. 2001. Orlando: SPIE.

13. Habersat, J., C. Marshall, and G. Maksymonko. NVESD mine lane facility. in Detection and Remediation Technologies for Mines and Minelike Targets VIII. 2003. Orlando: SPIE.

14. Fleming, K., J.M.H. Hendrickx, and S.-h. Hong, Regional mapping of root zone soil moisture using optical satellite imagery. Proc. International Society for Optical Engineering, SPIE, 2005. 5811: p. 159-170.

15. Hendrickx, J.M.H., et al., Estimation of regional actual evapotranspiration in the Panama Canal watershed, in The Rio Chagres: A multidisciplinary profile of a tropical watershed, R.S. Harmon, Editor. 2005, Springer: Dordrecht, The Netherlands. p. 315-324.

16. Hendrickx, J.M.H. and S.-h. Hong, Mapping sensible and latent heat fluxes in arid areas using optical imagery. Proc. International Society for Optical Engineering, SPIE, 2005. 5811: p. 138-146.

17. Hendrickx, J.M.H., et al., Mapping energy balance fluxes and root zone soil moisture in the White Volta Basin using optical imagery. Proc. International Society for Optical Engineering, SPIE, 2006: p. in press.

18. Hong, S.-h., J.M.H. Hendrickx, and B. Borchers, Effect of scaling transfer between evapotranspiration maps derived from LandSat 7 and MODIS images. Proc. International Society for Optical Engineering, SPIE, 2005. 5811: p. 147-158.

19. Miller, T.W., Radar detection of buried landmines in field soils, in Hydrology. 2002, New Mexico tech: Socorro. p. 124. 